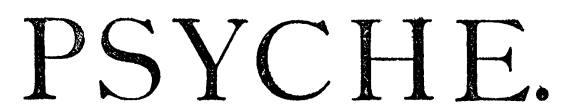

ORGAN OF THE CAMBRIDGE ENTOMOLOGICAL CLUB EDITED BY B. PICKMAN MANN.

Vol. I.] Cambridge, Mass., December, 1875. [No. 20.

\title{
On an Immense Flight of Small Butterflies (Terias lisa) in the Bermudas.
}

Marvellous indeed, as naturalists well know, are those periodic movements of the feathered race known as spring and autumn migrations. Moved by an instinctive impulse implanted in them by the Creator, thousands upon thousands of birds of all sizes, from the bulky swan to the tiny humming bird, travel by sea or land to distances so remote that, unless it was ascertained beyond doubt that the space was traversed, the fact would be considered almost ineredible.

But if we are greatly astonished at the power of endurance exemplified in this long sustained flight of some of the smallest birds, what will be said when we relate a circumstance connected with a similar power possessed by a species of butterfly, so small and apparently incapable of withstanding the violence of the elements, that we know not which is the more remarkable, the distance traversed, or the number of these frail little creatures which lived to reach those remote isles of the ocean, after an aerial journey of some six hundred miles or more?

Thus it was. Early in the morning of the first day of Oct. last year (1874), several persons living on the north side of the main island perseived, as they thought, a cloud coming over from the north west, which drew nearer and nearer to the shore, on reaching which it divided into two parts, one of which went eastward, and the other westward, gradually falling upon the land. They were not long in ascertaining that what they had taken for a cloud was an immense concourse of small yellow butterflies (Terias lisa Boisd.), which flitted about all the open grassy patches and cultivated grounds in a lazy manner, as if fatigued after their long voyage over the deep. Fisher- 
men out near the reefs, some few miles to the north of the islands, very early that morning, stated that numbers of these insects fell upon their boats, literally covering them. They did not stay long upon the islands, however, only a few days, but during that time thousands must have fallen victims to the vigorous appetites of the blue bird (Sialia sialis Baird) and black bird (Mimus carolinensis Gray), which were continually preying upon them. Only one other instance of a flight of these butterflies visiting the islands is recorded (in the author's "Naturalist in Bermuda" p. 120).

The migratory habit of the Pieridae, to which the present species belongs, is well known, and notices of the occurrence of large flights have occasionally appeared in entomological journals. Numbers of Pieris napi and P.brassicae have been known to cross the channel from France to England, and a migratory host of Callidryas radia has been observed moving along in Basuto Land; but the only instances published of their having been met with at sea, are to be found in Darwin's "Naturalist's Voyage" and the "Entomologist's Magazine" (England).

Darwin writes as follows : - Several times when the ship (H. M. S. "Beagle") has been some miles off the mouth of the Rio Plata, and at other times when off from the shores of northern Patagonia, we have been surrounded by insects. One evening, when we were about ten miles from the Bay of San Blas, vast numbers of butterflies, in bands or flocks of countless myriads, extended as far as the eye could range. Even by the aid of a telescope it was not possible to see a space free from butterflies. The seamen cried out " it was snowing butterflies," and such in fact was the appearance. More species than one were present, but the main part belonged to a kind very similar to, but not identical with, the common English Colias edusa. Some moths and Hymenoptera accompanied the butterflies, and a fine beetle (Calosoma) flew on board. The day had been fine and calm, and the one previous to it equally so, with light and variable airs. Hence we cannot suppose that the insects were blown off the land, but we must conclude that they voluntarily took flight. The great bands of the Colias seem at first to afford an instance like those on record of the 
migrations of another butterfly, Vanessa cardui (Lyell's Principles of Geology, vol. iii, p. 63), but the presence of other insects makes the case distinct and even less intelligible. Before sunset a strong breeze sprung up from the north, and this must have caused tens of thousands of the butterflies and other insects to have perished.

In the Entomologist (vol. iii, p. 226) it is stated that during a cyclone, and at a distance of 600 miles from the African coast and 200 from the Cape Verde islands, a vessel was visited by numerous birds and butterflies, the latter being Diadema bolina and Pyrameis cardui.

Now the instance related by Darwin only proves the fact of flocks of butterflies being observed ten miles from land, and that recorded in the Entomologist leares it an open question as to whether the insects were direct from the coast of Africa or Cape Verde Is., ${ }^{1}$ or indeed whether they occurred in remarkable numbers. We have, therefore, reason to believe that the vast host of Terias lisa which arrived at the Bermudas on the 1st of October last, and that visitation recorded in the "Naturalist in Bermuda" as occurring on the 10th of October 1847, are the only instances known of such extraordinary flights of Lepidoptera, or indeed any insects being met with at such an amazing distance from land.

The question, therefore, naturally arises - How did this immense concourse of butterflies get to the Bermudas? The nearest point of land is Cape Hatteras, in North Carolina, which is somewhere about 600 miles distant, and if they had started from this point and taken a straight line to the islands, without meeting with any contrary winds, it would, at the rate of 12 miles per hour (a fair average rate of travel for any of the Pieridae), have taken them two days and two hours (of course including nights) to complete the distance; a space of time almost too great, we should imagine, for an insect in no degree remarkable for robust frame or strength of wing to keep up a continuous flight. We are, however, inclined to think that the presence of this vast concourse of insects at the Bermudas was

1 I do not find any record of the occurrence of $P$. cardui in the Cape de Verde islands, although it is found on the islands to the north. $-S$. H. Scudder. 
not owing to ordinary causes, and that we must look to some extraordinary means to solve the mystery. From a very extended series of observations made at intervals during the last twenty years, with the view of throwing light upon the migration of North American birds to those islands, we have become impressed with the fact that the largest flights of birds occur there during the period of great atmospheric disturbance. From the latter end of September to that of October, violent revolving gales are prevalent throughout the region which comprises the east coast of the Southern and Middle ${ }^{1}$ States and the North Atlantic in those latitudes, for some 600 or 800 miles from land. At this particular period vast flights of birds of all kinds are proceeding sonthwara along the coast for their winter resorts in Florida, West Indies and South America, and must often meet with the violent gales we have alluded to. Now the observations of scientific aeronauts, like Glaishier and others, teach us that the upper atmosphere is composed of currents of air differing in their courses as elevation proceeds, and some cases are on record in which balloons at a great height have suddenly come in contact with violent direct gales, which carried them onward with such velocity as to render their course one of extreme peril, only escaping destruction by the superior manœurring of those in charge. Let us suppose a violent revolving gale passing along the coast of the Southern States, about the latitude of the Bermudas, during the period of the autumnal migration of birds and butterflies, engulphing some of those great flights which are then proceeding along in a southerly direction. Drawing them up high in its vortex, a direct westerly gale is met with, blowing with great force out to sea. Hurled with amazing rapidity along this cool aerial current, in the course of about three or four hours the heated vapor arising from the Gulf Stream would be met with, and would it be considered as too imaginative to grant that the ascending warmth of that stream has power sufficient to ameliorate the condition of the cool current, to stay its rapid course

1 Terias lisa occurs along the Atlantic Coast from New Hampshire to Cuba. It is excessively rare north of Cape Cod, common from New Jersey to Cape Hatteras, and extremely abundant farther South. $-S . H$. S. 
and allow the animal freight to descend, which, then within a comparatively short distance of the Bermudas, would seek the nearest land by that instinctive impulse so characteristic of these tribes, and aided perhaps by perfect calm or favoring breeze, arrive at those distant isles, without encountering the dangers, which, in the form of contrary winds, would most certainly accompany an intentional migration to the islands? If our theory, however, be an incorrect one, as it may be, we should indeed be glad if some one would lend a helping hand to solve this question of a migration of tiny butterflies from the American main to those small and remote isles, six hundred miles away over the rolling waters of the trackless deep.

$$
\text { Halifax, N. S., Nov. 15, } 18 \% 5 \text {. }
$$

J. Matthew Jones.

\section{BIBLIOGRAPHICAL RECORD.}

Authors and Societies are requested to forward their works to the Editor at the earliest date possible. We ask our readers to inform us of the publication especially of those works which are not generally consulted by entomologists.

B. Pickman Mann.

(Continued from porge 120.)

\section{The Transactions of the American Entomological}

Society, vol. v, as far as p. 118, contain Nos. 318 to 331 .

* 318. G. H. Honn. Revision of the Species of Trox of the United States. p. 1-12.

Description, with synoptical tables, of 21 ( $T$. gemmulatus $=1$ new) spp.

* 319. W. H. Edwards. Descriptions of New Species of Diurnal Lepidoptera found in North America. p. 13-19.

Describes Argynnis Rhodope, A. Nitocris, Satyrus Phocus, Melitaea Acastus, Synchloë Crocale, Geirocheilus Tritonia $=6$ n. spp.; re-describes Erebia Haydenii ; list of 13 other butterfties, taken in British Columbia and Vancouver's Island.

* 320. G. H. Horn. Descriptions of New Species of United States Coleoptera. p. 20-43.

Describes Cychrus mimus, Hetaeriws tristriatus, Paromalus difficilis, Nosodendron californicum, Esthesopus bicolor, Elater Phelpsii, Glyphonyx mimeticus, Oestodes puncticollis, Aplastus angusticollis, A. tenuiformis, A. corymbitoides, A. molestus, Malachius macer, M. spinipennis, M. Thevenetii, Stibia ovipennis, S. hispidula, Chilometopon (n. g. Epitragini), Ch. helopioides, Schizillus (n. g. Cryptoglossini), S. laticeps, Eleodes velorator, Iphthimus 

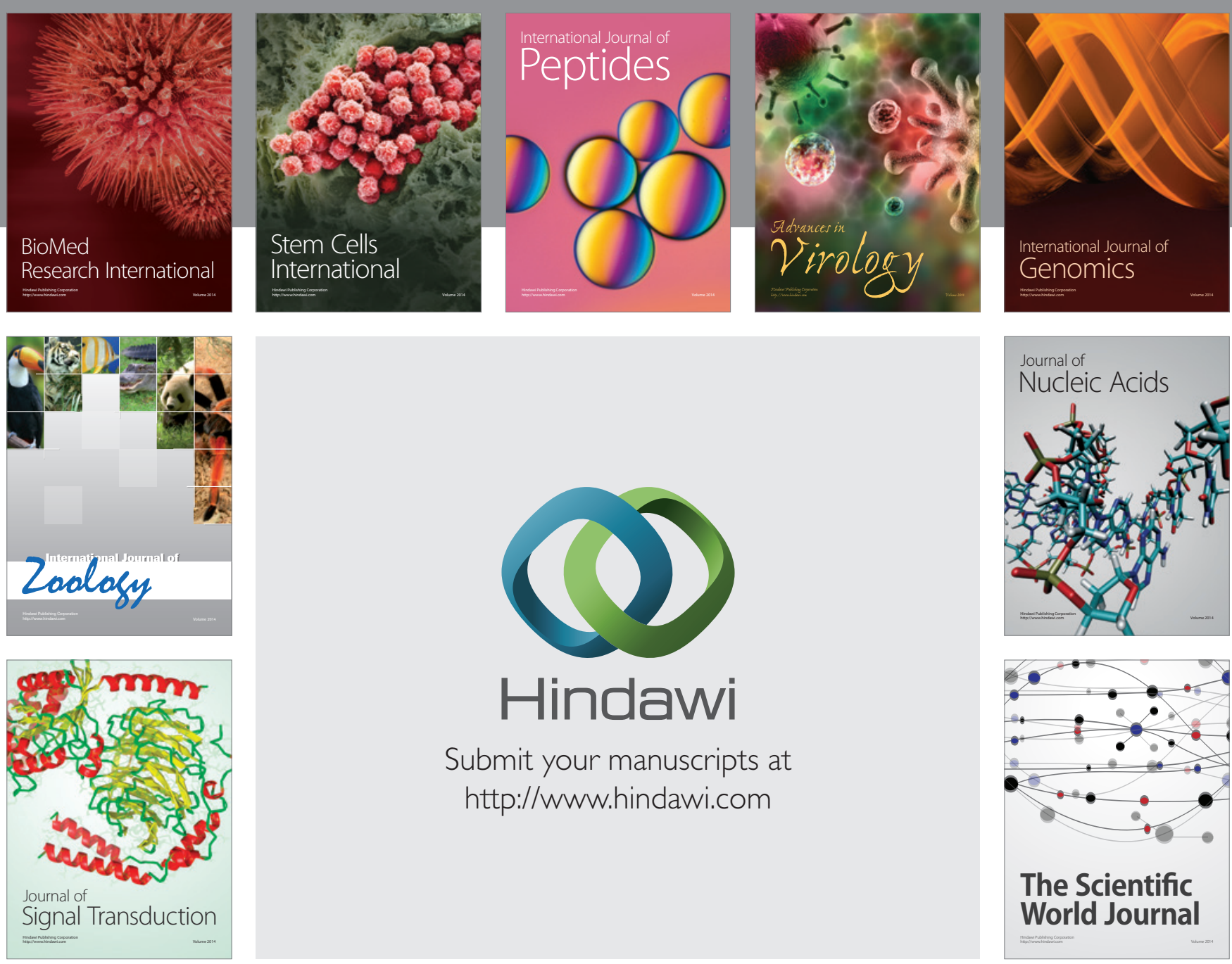

Submit your manuscripts at

http://www.hindawi.com
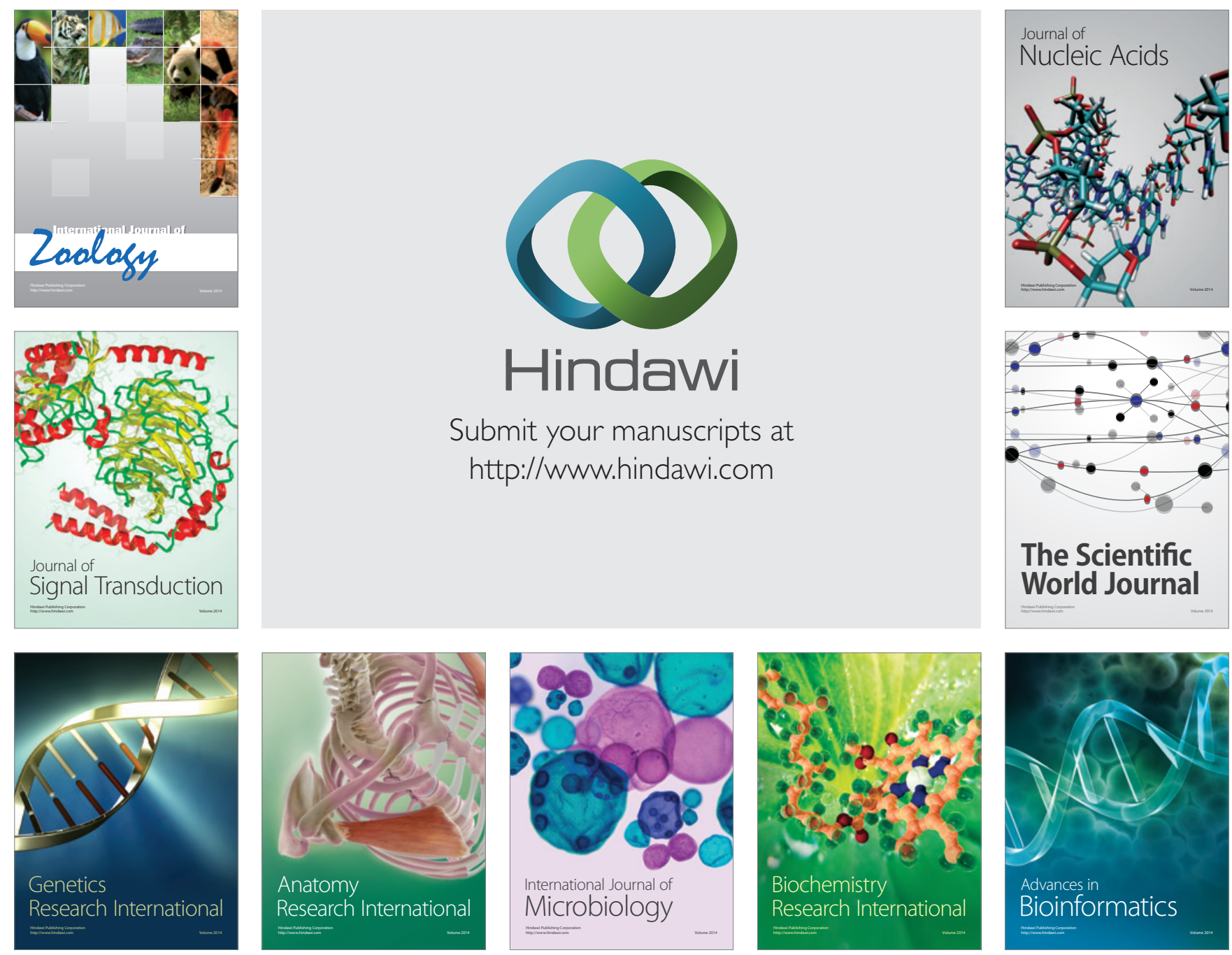

The Scientific World Journal
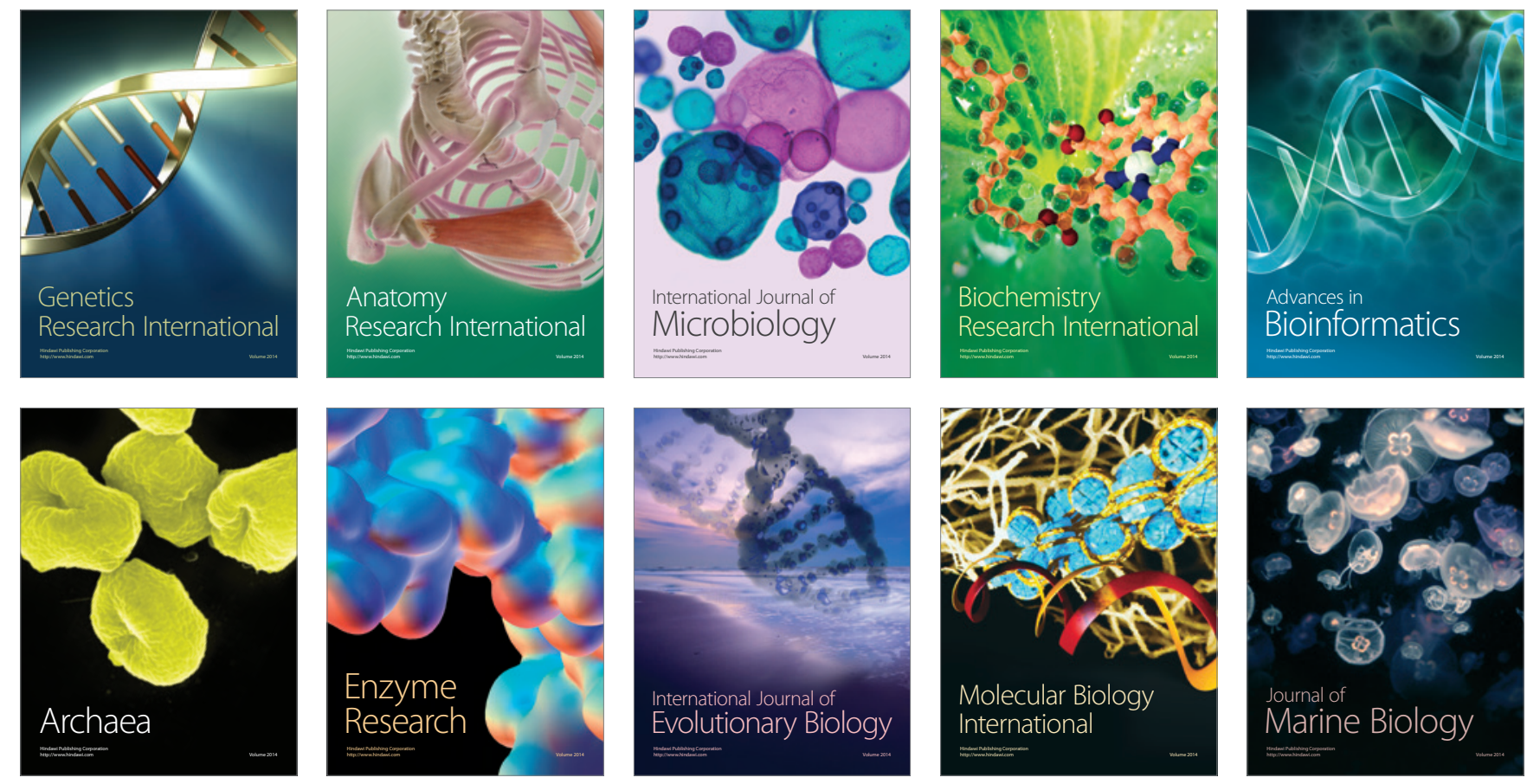